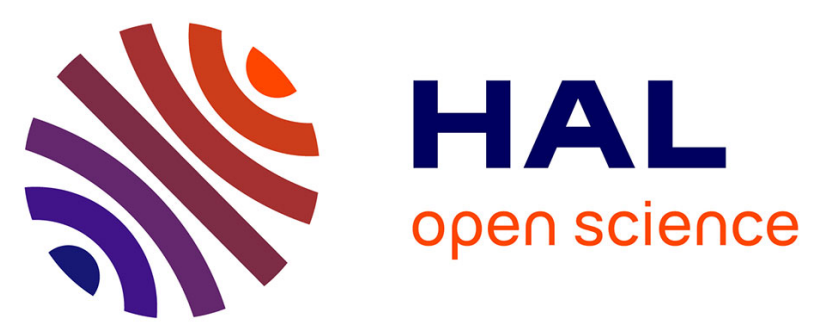

\title{
Postoperative control in deep brain stimulation of the subthalamic region: the contact membership concept
} Simone Hemm, François Caire, Jerome Coste, François Vassal, Christophe Nuti, Philippe Derost, Lemlih Ouchchane, Laurent Sarry, Franck Durif, Jean-Jacques Lemaire

\section{To cite this version:}

Simone Hemm, François Caire, Jerome Coste, François Vassal, Christophe Nuti, et al.. Postoperative control in deep brain stimulation of the subthalamic region: the contact membership concept. International Journal of Computer Assisted Radiology and Surgery, 2008, 3 (1-2), pp.69 - 77. 10.1007/s11548-008-0152-6 . hal-01550126

\section{HAL Id: hal-01550126 \\ https://hal.science/hal-01550126}

Submitted on 29 Jun 2017

HAL is a multi-disciplinary open access archive for the deposit and dissemination of scientific research documents, whether they are published or not. The documents may come from teaching and research institutions in France or abroad, or from public or private research centers.
L'archive ouverte pluridisciplinaire HAL, est destinée au dépôt et à la diffusion de documents scientifiques de niveau recherche, publiés ou non, émanant des établissements d'enseignement et de recherche français ou étrangers, des laboratoires publics ou privés. 


\section{Postoperative control in deep brain stimulation of the subthalamic region: the contact membership concept}

Simone Hemm (1,2), François Caire (3), Jérôme Coste (2), François Vassal (4), Christophe Nuti (4), Philippe Derost (5), Lemlih Ouchchane (6), Laurent Sarry (1), Franck Durif (5), Jean-Jacques Lemaire $(1,2, *)$

1.Inserm, ERI 14, Equipe de Recherche en Imagerie Médicale, Clermont-Ferrand, France

2.CHU Clermont-Ferrand, Hôpital Gabriel-Montpied, Service de Neurochirurgie A, Clermont-Ferrand, France

3.CHU Limoges, Hôpital Dupuytren, Service de Neurochirurgie, Limoges, France

4.CHU Saint-Etienne, Hôpital Hôpital Bellevue, Service de Neurochirurgie, Saint-Etienne, France

5.CHU Clermont-Ferrand, Hôpital Gabriel-Montpied, Service de Neurologie, ClermontFerrand, France

6.Université Clermont-Ferrand 1, UFR Médecine, Unité de Bio statistiques, télématique et traitement d'image, Clermont-Ferrand, France

*Corresponding author : jjlemaire@chu-clermontferrand.fr

KEYWORDS: STN-DBS, Direct targeting, MRI, Postoperative control, Contact mapping 


\section{ABSTRACT}

\section{Object}

In deep brain stimulation, the anatomic positions of electrode contact centers are used as the basis for analysis. We propose a new semi-quantitative approach (contact membership concept) considering patient's individual anatomy, contact size, and extent of involvement of STN and neighboring structures.

\section{Materials and methods}

In ten bilaterally operated and improved Parkinsonian patients, effective contact positions (contacts used for monopolar stimulation) were analyzed. The position of the contact center (classical binary approach: each center assigned, 1, or not, 0 , to a given structure) and of the contact in its dimension (contact membership concept: membership degree, ordinal values from 0 to 1, assigned to each anatomic structure according to extent of involvement) were compared for the whole patient group and, individually, for each patient.

\section{Results}

The membership concept revealed that for 13 out of 20 contacts, more than one structure was involved, where the classical binary approach assigned only one structure. For both approaches lateral STN, zona incerta and H1 (Forel's Field) were the main structures involved, but their frequencies of appearance differed.

\section{Conclusion}

The membership concept allows detailed analysis of the anatomic contact position. In the future this approach could assist in correlating anatomy and clinical results for all electrode contacts (effective ones and clinically less efficient ones). 


\section{INTRODUCTION}

Deep brain stimulation (DBS) of the subthalamic nucleus (STN) has proved to be a highly effective treatment of symptoms related to severe idiopathic Parkinson's disease (PD) [1-4]. However, the anatomic structures affected by stimulation, and therefore the underlying mechanisms of action of DBS, have not yet been determined [5-10]. The success of DBS electrode implantation resides essentially in the relief of symptoms, but the position of electrode contacts needs to be determined in terms of anatomic position. More and more groups advocate postoperative imaging (magnetic resonance imaging MRI/computer tomography $\mathrm{CT}$ ) to check for absence of hemorrhage and determine the final electrode position in comparison with the planned one [11-13]. Only a few of these groups determine the contact positions and correlate them with anatomy $[6,8,9,14-18]$. Still fewer groups base this analysis on the patient's MRI alone without atlas projection $[13,14,17]$. Nearly all of the groups performing a detailed anatomic study localize the anatomic position of centers of the electrode contacts. They do not consider the contact in its dimension $[6,13-16,18,19]$.

The work reported here describes the postoperative position analysis of the clinically effective contacts, i.e., contacts used for chronic stimulation, based on individual patient anatomy. In accordance with our targeting concept (preoperative direct targeting linked to manual structure segmentation), it is based on the visual analysis of pre- and postoperative MR images. As the electrode size (diameter $=1.27 \mathrm{~mm}$; height $=1.5 \mathrm{~mm}$ ) is significant compared with the functional targets, it is often difficult to assign a given contact to a single brain structure. We therefore propose a new semi-quantitative approach, the contact membership concept, which takes into account the extent of involvement for each anatomic structure, i.e., the initial target, the STN, and its neighborhood. The classical binary approach, i.e., where the center of the contact is (1) or is not (0) in a given structure, differs from our membership concept, where the whole contact is related to different structures: anatomic membership of a contact; ordinal values from 0 to 1 , weighting the geometric relationships with the structures. 


\section{MATERIALS AND METHODS}

\section{Patients}

Ten patients suffering from severe idiopathic Parkinson's disease and treated by bilateral monopolar STN-high frequency stimulation according to the guidelines of the French National Health Agency for Accreditation and Evaluation were included in this study [5 males, 5 females; age $61.8 \pm$ 8.1years, duration of disease $12.7 \pm 5.2$ years (mean \pm SD)]. Their clinical improvement was evaluated using the unified Parkinson's disease rating Scale (UPDRS) [20]. It was determined in OFF-drug condition (for at least $12 \mathrm{~h}$ ) with a mean voltage of $2.6 \pm 0.5 \mathrm{~V}$ (frequency $136.0 \pm 12.3 \mathrm{~Hz}$, pulse width $63.0 \pm 9.2 \mu \mathrm{sec}$ ). Global improvement after 3 months of follow-up was $50.9 \pm 12.0 \%$ (range 33.7-71.4\%). The lateralized UPDRS III mean motor subscore improvement (sum of items 20-26 for each body side, resulting in a score range of 036 ), was $61.8 \pm 16.1 \%$ (range $40.0-100.0 \%$ ). This measure reflects the degree of tremor, rigidity, and bradykinesia in the left and right extremities, excluding axial symptoms, and has already been proposed by other authors for the evaluation of the contralateral effects of left and right electrodes $[9,18]$. Contacts resulting in the best alleviation in rigidity with the lowest voltage and without significant side effects were considered as optimal and selected for chronic stimulation as the effective contacts. The total number of effective contacts available for analysis was 20 (pooling right and left sides).

\section{Surgical procedure}

Stereotactic electrode implantation (Leksell G frame, Elekta, Sweden) was performed under local anesthesia in a 2 day procedure. A preoperative T2-weighted stereotactic MRI was obtained and the STN and neighboring structures were identified and segmented manually using stereotactic software (iPlan, Brainlab, Germany). On the first day we performed a White Matter Attenuated Inversion Recovery (WAIR) T2-weighted sequence (Table 1) to visualize both the stereotactic markers and the subthalamic anatomy of nuclei and bundles [13,21]. Several structures of the subthalamic region were outlined manually on the coronal plane (see example Fig. 3): STN, zona incerta $(\mathrm{ZI})$, substantia nigra $(\mathrm{SN})$, red nucleus $(\mathrm{RN})$, nucleus ansa lenticularis $(\mathrm{AL})$, the $\mathrm{H} 1$ 
(thalamic fascicule) or H2 (lenticular fascicule) Forel's fields (FF), the mamillo-thalamic bundle (MTB), the ventral thalamus (Thal) and the periventricular region (PVR). The recognition of the anatomy was achieved through a step-by-step approach starting from the easiest identification of simple shaped and located structures such as SN, RN and STN [13]. According to the relative position and with the help of anatomic and stereotactic books and in-house 4.7-tesla (T) MRI anatomy software an accurate 3D multiplane analysis was then possible [13,14,22,23].

\begin{tabular}{|c|c|c|c|c|c|c|c|}
\hline Sequences & $\begin{array}{l}\text { Repetition/echo } \\
\text { time (ms) }\end{array}$ & $\mathrm{TI}(\mathrm{ms})$ & Voxel size $\left(\mathrm{mm}^{3}\right)$ & Field of view $(\mathrm{mm}) /$ matrix & $\begin{array}{l}\text { Number } \\
\text { of } \\
\text { images }\end{array}$ & Acquisition & Orientation \\
\hline $\begin{array}{l}\text { T2- } \\
\text { weighted: } \\
\text { white matter } \\
\text { attenuated } \\
\text { inversion } \\
\text { recovery } \\
\text { (WAIR) }\end{array}$ & $4,500 / 13$ & 160 & $0.52 \times 0.62 \times 2$ & $270 / 512 \times 435$ & $\begin{array}{l}2 \times 15 \\
\text { (two } \\
\text { inter- } \\
\text { leaved } \\
\text { series; } \\
\text { distance } \\
\text { factor }= \\
2 \mathrm{~mm} \text { ) }\end{array}$ & $2 \times 9 \min 33 s$ & Coronal \\
\hline $\begin{array}{l}\text { T1- } \\
\text { weighted: } \\
\text { 3D- } \\
\text { MPRAGE }\end{array}$ & $2,140 / 3.93$ & n.a. & Isotropic: 1.3 & $320 / 480 \times 512$ & $\begin{array}{l}120 \\
\text { (joined) }\end{array}$ & $8 \min 18 s$ & Axial \\
\hline
\end{tabular}

Table 1. Technical characteristics of MRI sequences using a head coil: pre-operative, stereotactic (stereotactic frame in place), T2-weighted; post-operative, non-stereotactic, T1weighted, Specific absorption rate $=0.1 \mathrm{~W} / \mathrm{kg}$.

On the second day, after repositioning of the stereotactic frame (Repositioning kit, Elekta, Sweden), the optimal target was defined under local anesthesia based on the anatomic information, intraoperative microelectrode recording (MER) and the clinical benefit and adverse effects assessment following a gradual acute stimulation. A quadripolar electrode (DBS 3389, Medtronic, USA) was placed during the same procedure with the center of contact 1 (right electrode) or 5 (left electrode), located just above the distal contact ( 0 , right electrode or 4 , left electrode) on this optimal point. Anysignificant brain shift and electrode misplacement (checked by intra and postoperative radiologic controls) were avoided during the bilateral electrode implantation thanks to precautions: (1) the patient operated in a recumbent position in order to maintain a positive intracranial pressure, (2) the "closed dura matter" approach allowed by water-air tight guides (Bengun, Immi, France), (3) double obliquity trajectories in order to avoid ventricles, (4) two exploration tracts (two long guide-tubes) and (5) brain maintained by one guide-tube (on the trajectory which was not selected after the intraoperative tests) while the DBS 
electrode is placed coaxially along the selected tract. To check the final electrode position, a stereotactic X-ray control (based on Leksell Coordinates Indicator Box) was performed directly after electrode placement, and a T1-weighted, non-stereotactic 3D-MPRAGE MRI control in the axial plane (Table 1) within 2days. A neuropacemaker (Kinetra, Medtronic, USA) was implanted in the abdominal region under general anesthesia some days later.

\section{Contact localization}

Following our surgical procedure, the final electrode position could be determined via the postoperative MRI control. To collect preoperative stereotactic data, the segmented structures and the planned trajectories on the postoperative MRI, we merged postoperative (non-stereotactic) MRI with preoperative (stereotactic) MRI using the mutual information algorithm (iPlan, BrainLAB, Germany) [24,25]. The final electrode position was determined based on the black electrode artifact on the postoperative MRI. As shown elsewhere, the real electrode position can be assigned to the middle of the artifact [26]. The position of each contact was calculated starting from the middle of the artifact (the center position enclosed by the four contacts of the electrode) and based on the known theoretical electrode dimensions (DBS 3389: 7.5mm between the ends of the proximal and distal contacts, $0.5 \mathrm{~mm}$ between contacts). The anatomic relationships of the contacts were determined on reconstructed images along the electrode to optimize the interpretation of anatomic position.

\section{Definition of the anatomic position}

The analysis of the anatomic position of a given contact was performed using three views along the electrode (called "pseudo" coronal, sagittal and axial). We considered the contact position in relationship with the neighboring structures, i.e., the STN, ZI, SN, AL, Forel's fields H1 and H2, and the ventral thalamus. The STN was subdivided into three different parts, a lateral superior part (lat-sup STN), an intermediate part (int STN) and a medial inferior part (med-inf STN).

The identification was performed in two different ways: 
1. Classical approach: contact center-one structure (binary: 0/1). Only one anatomic structure was assigned to the effective contact according to the projection of the center of this contact.

2. Membership concept: contact in its size—several structures (ordinal values: from 0 to 1 ).

To take into account the imprecision, especially the one linked to the MRI resolution, we chose a mathematical model based on the variable "degree of membership" used in fuzzy logic introduced by Zadeh [27,28]. We subjectively assigned a weight to each anatomic structure covered by the effective contact. The weight resulted from the ordinal coding accounting for the membership degree and from the different anatomic configurations. When the contact could be clearly assigned to only one structure, the weighting was obviously set to 1 . When several structures were involved, we distinguished between main and secondary structures according to the size of the contact part lying within the considered structure. The larger the number of structures involved, the lower the weighted values assigned to the structures (Table 2, Fig. 1). If there is only one structure that can be defined as a main structure but if the "contact" is shared with other structures involved in a lesser extent (see secondary structure), the weight for that main structure is set to 0.8. If there are several structures that can be defined as main structures, the weights of these structures are set to 0.5 each, if they are the only structures involved. In the case of several main structures, their weights are set to 0.4 each if other (secondary) structures are also involved. A structure is referred to as secondary structure if the extent of its contact is considered as "minor". Whatever the configuration and the number of structures involved, the weight for a secondary structure is set to 0.25 .

\begin{tabular}{lll}
\hline Involved structures & Main structure & Secondary structure \\
\hline 1 Main & 1 & 0 \\
1 Main $+n$ secondary & 0.8 & 0.25 \\
$N$ Main +0 secondary & 0.5 Each & 0 \\
$N$ Main $+n$ secondary & 0.4 Each & 0.25 Each \\
0 Main $+n$ secondary & 0 & 0.25 Each \\
\hline
\end{tabular}

Table 2. Membership degree (from 0 to 1) of given anatomic structures according to the extent of their involvement for a considered contact; main: principal structure covered by a large part of the contact; secondary: secondary structure covered by a small part of the contact. 


\section{Data analysis}

For each active contact $(n=20)$, we classified the anatomic relationships as described above. For each structure we calculated the sum of all contact memberships, once with the binary-center approach and once with the contact membership concept. Then the percentage of involvement of each structure was calculated. Mean and standard deviations of the weightings for each structure were additionally determined. We confronted, for each patient separately, the results obtained with the membership concept with those of the classical approach based on the center of the contact.
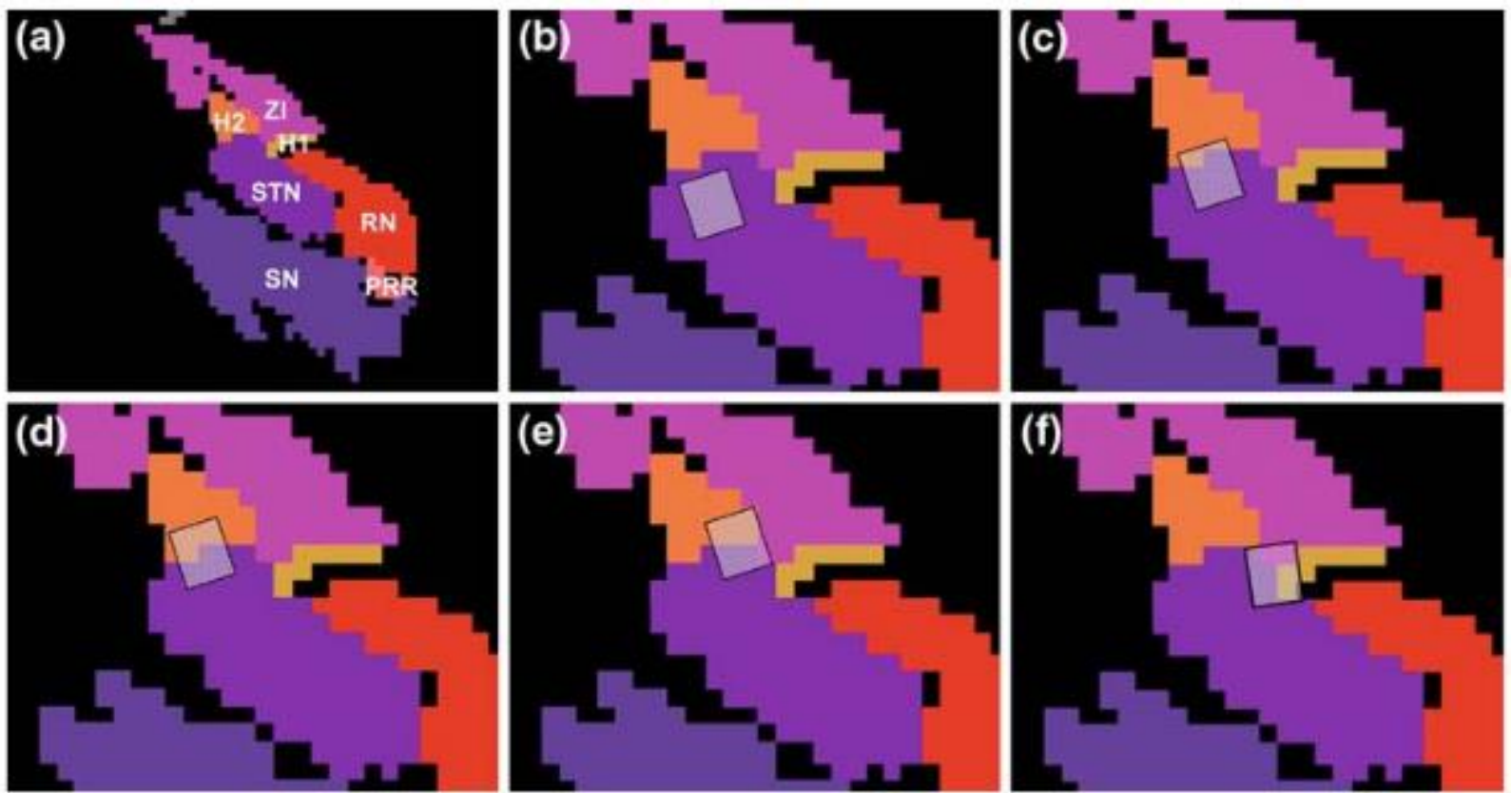

Figure 1. Presentation of the contact membership concept on identified structures after manual outlining on original MRI slices. a The entire region of interest around the STN . $b$ The contact can be clearly identified within one single structure (STN:1). c The contact is largely covered by one structure (STN:0.8) and marginally by one or more other structures (H2:0.25). d Two mainstructures (STN:0.5, H2:0.5). e Main (STN:0.4,H2:0.4) and secondary (ZI:0.25) structures. $f$ Only secondary structures (ZI:0.25,STN:0.25, H1:0.25). STN subthalamic nucleus, SN substantia nigra, RN red nucleus, H1 H1 Forel's field (thalamic fascicle), H2 H2 Forel's field (lenticular fascicle), ZI zona incerta, PRR prerubral region 


\section{RESULTS}

The image series of the ten patients could all be analyzed for the right and left electrodes. Accordingly, we explored the anatomic position of 20 active contacts.

With both approaches (center of contact and whole contact), the lateral part of the STN, the Forel field $\mathrm{H} 1$ and the zona incerta can mostly be found in the vicinity of the contact (Fig.2). One essential difference between the approach using only the contact center and the one using the whole electrode contact is that the intermediate STN appears rarely and the AL not at all in the first approach.

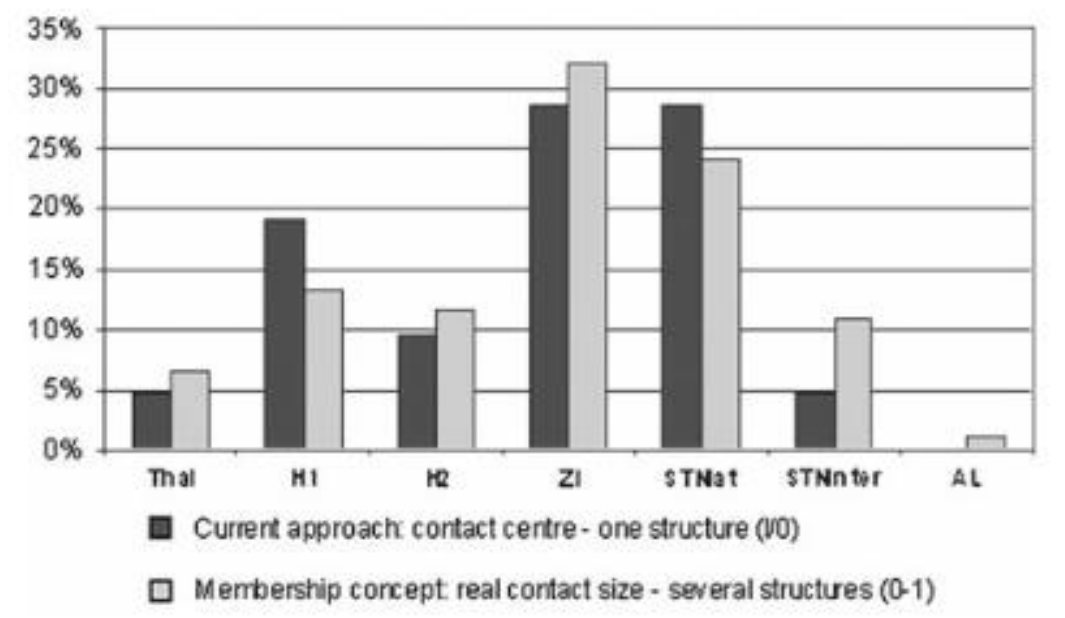

Figure 2. Percentage involvement of each structure according to the classical binary classification (0 or 1) based on only the contact center, and according to the contact membership concept (between 0 and 1) taking into account the whole contact size.

In the classical approach, based on the contact center, the structures most often involved were the lateral STN and the zona incerta (28.6\%), followed by the Forel field H1 (19.1\%). With the membership approach the frequency of appearance changed, the ZI became more frequent than the lateral STN (ZI: $32.0 \%$, STN: 24.1\%). The intermediate STN and the Forel Field H2 became almost as frequent as the $\mathrm{H} 1$ (H1: 13.37\%, H2: 11.7\%, int STN: 10.98\%).

The analysis of each patient separately (Table 3, Fig.3) confirmed that lateral STN and ZI were the structures most often involved (10 out of 20 cases, for each structure) and that in general at least one of the two structures could be found close to the contact. Forel's Fields H1 (7/20) and H2 (6/20) also appeared regularly. 
The contact center approach assigns one structure to each contact (Table 3, grey cells). With the contact membership approach, we obtained such a result, i.e., only one involved structure, in only 7 out of 20 cases (Table 3, structures set to "1"). In the other 13 cases, one or two other additional structures appeared. In addition, we identified, for each contact, the structure(s) presenting the highest membership degree: in 12 cases there was only one structure with the highest membership degree (Table 3, structures set to “*”), while in 8 cases there were several principal structures with the same extent of involvement.

\begin{tabular}{|c|c|c|c|c|c|c|c|c|c|c|}
\hline \multirow[t]{2}{*}{ Patient } & \multirow[t]{2}{*}{ Side } & \multirow[t]{2}{*}{ Effective contact } & \multirow{2}{*}{$\begin{array}{l}\text { Clinical motor } \\
\text { improvement }(\%)^{\mathrm{a}}\end{array}$} & \multirow[t]{2}{*}{ Zona Incerta } & \multirow[t]{2}{*}{$\mathrm{AL}$} & \multicolumn{2}{|c|}{ Forel's fields } & \multirow[t]{2}{*}{ Motor thalamus } & \multicolumn{2}{|c|}{ STN segments } \\
\hline & & & & & & $\overline{\mathrm{H} 1}$ & $\mathrm{H} 2$ & & Lat-sup. ${ }^{b}$ & Int \\
\hline \multirow[t]{2}{*}{1} & $\mathrm{R}$ & 2 & 42 & & & & & & $l^{\mathrm{ab}}$ & \\
\hline & L & 4 & 60 & & & 0.5 & & & 0.5 & \\
\hline \multirow[t]{2}{*}{2} & $\mathrm{R}$ & 2 & 53 & 0.25 & & $0.4^{\mathrm{b}}$ & & & 0.25 & \\
\hline & $\mathrm{L}$ & 7 & 69 & $l^{\mathrm{b}}$ & & & & & & \\
\hline \multirow[t]{2}{*}{3} & $\mathrm{R}$ & 2 & 53 & $0.8^{\mathrm{b}}$ & & & 0.2 & & & \\
\hline & $\mathrm{L}$ & 6 & 44 & & & & & & & $I^{\mathrm{b}}$ \\
\hline \multirow[t]{2}{*}{4} & $\mathrm{R}$ & 2 & 53 & & & 0.5 & 0.5 & & & \\
\hline & $\mathrm{L}$ & 5 & 64 & 0.25 & 0.25 & & $0.8^{\mathrm{b}}$ & & & \\
\hline \multirow[t]{2}{*}{5} & $\mathrm{R}$ & 2 & 64 & & & & & & $l^{\mathrm{b}}$ & \\
\hline & $\mathrm{L}$ & 6 & 77 & 0.4 & & & 0.4 & & 0.25 & \\
\hline \multirow[t]{2}{*}{6} & $\mathrm{R}$ & 2 & 80 & $l^{\mathrm{b}}$ & & & & & & \\
\hline & $\mathrm{L}$ & 5 & 86 & & & 0.5 & & & 0.5 & \\
\hline \multirow[t]{2}{*}{7} & $\mathrm{R}$ & 1 & 100 & & & & & & 0.5 & 0.5 \\
\hline & L & 6 & 46 & $0.8^{\mathrm{b}}$ & & & 0.25 & & 0.25 & \\
\hline \multirow[t]{2}{*}{8} & $\mathbf{R}$ & 1 & 75 & & & & 0.25 & & 0.4 & 0.4 \\
\hline & $\mathrm{L}$ & 6 & 40 & & & & & $l^{\mathrm{b}}$ & & \\
\hline \multirow[t]{2}{*}{9} & $\mathrm{R}$ & 1 & 79 & & & 0.25 & & & 0.4 & 0.4 \\
\hline & L & 6 & 55 & 0.25 & & 0.4 & & 0.4 & & \\
\hline \multirow[t]{2}{*}{10} & $\mathrm{R}$ & 2 & 50 & $l^{\mathrm{b}}$ & & & & & & \\
\hline & $\mathrm{L}$ & 6 & 46 & $0.8^{\mathrm{b}}$ & & 0.25 & & & & \\
\hline \multicolumn{3}{|c|}{ Mean \pm SD } & $61.8 \pm 16.1$ & & & & & & & \\
\hline \multicolumn{3}{|c|}{ Membership degree } & Sum & 6.55 & 0.25 & 2.8 & 2.4 & 1.4 & 5.05 & 2.3 \\
\hline
\end{tabular}

Table 3. Analysis of the position of effective contacts $(n=20)$ for the ten patients (right $R$ and left L electrodes) by the membership concept (considering contact size).

The structures involved according to the binary classical approach (only considering contact center) are given in italics AL nucleus ansa lenticularis, lat-sup lateral superior part of the STN, int intermediate part of the STN

a: Clinical motor improvement expressed in percentage based on the UPDRS motor score: (preoperative score - postoperative score)/ postoperative score $\times 100$.

$b$ : Only one main structure has been identified by the membership concept and that this structure corresponds to the one involved according to the binary concept. Cases where there are several main structures are not included ( 8 out of 20 cases) 

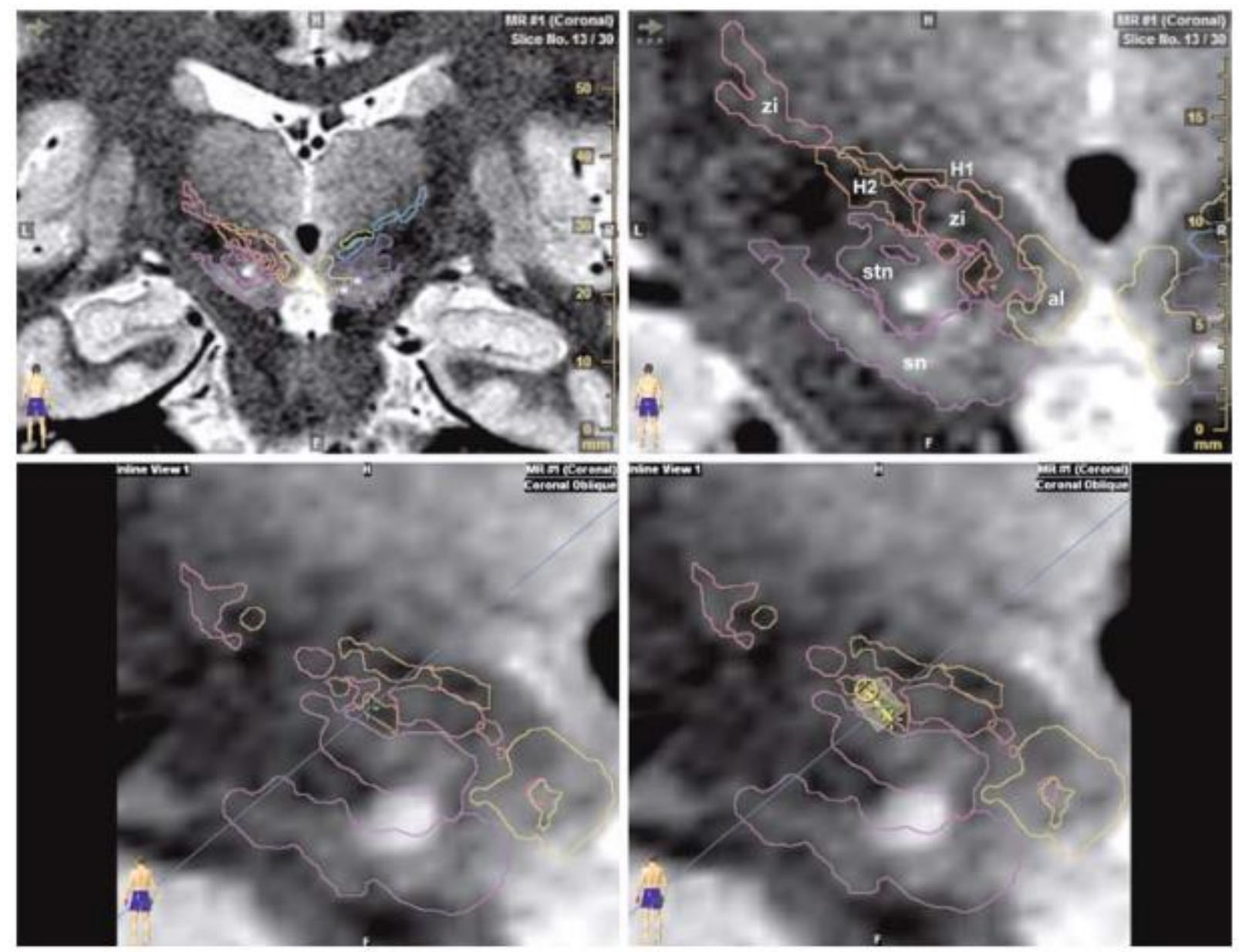

Figure 3. Example for one patient: (Top) original coronal raw images with the outlines of anatomic structures (top row; left, overview; right, zooming, labelled structures); (Bottom) reconstructed MRI plane, pseudocoronal, along the electrode trajectory (bottom row); analysis according to the contact center ( left) or the whole contact ( right). Following the first approach only one structure is involved against three in the second one.

H1 H1 Forel's field (thalamic fascicle), H2 H2 Forel's field (lenticular fascicle), al ansa lenticularis complex, stn subthalamic nucleus, sn sustantia nigra, zi zona incerta. 


\section{DISCUSSION}

Post-placement imaging is mainly used to check for absence of hemorrhage and also increasingly to analyze the final electrode position in DBS. The anatomic position of a given contact is less frequently sought. In most teams the anatomic position is determined on the postoperative MR images $[13,14,17,29]$ or on X-ray controls $[8,18]$; it is assumed that there is no significant brain shift which might cause misinterpretations [30,31]. On the MR images the center of the artifact is generally considered as the middle of the four contact location [26] and the different electrode contacts are deduced manually [14,16,17] or automatically [32]. Pre- and postoperative MR image matching based on the mutual information algorithm [25] has been shown to be reliable [24] and thus can be used to analyze the contact position relative to MRI anatomy. On stereotactic X-ray images, contacts are visible separately and their positions can be determined directly, in general manually, in the stereotactic reference system [18,33].

Unfortunately, it is difficult to compare results obtained with the different methods applied to localize a contact and the surrounding structures. The analysis has three different characteristics: (1) how the contact is represented, as a point or with its real dimensions; (2) the anatomic reference used (atlas, MRI, electrophysiologic study); and (3) how the contact membership is interpreted (assignment to one or several structures, weighted or non-weighted). In the following section we discuss these three features.

\section{Contact representation}

Most groups analyze the active contact position by projecting the center of the contact on the anatomy [6,14-16,18,19]. Herzog et al. [8] took into account the height of the contact $(1.5 \mathrm{~mm})$. None of the groups considered the real contact size. This may have been for technical reasons, such as the chosen anatomic reference (see below): when a classical stereotactic atlas is used, the contact cannot be visualized along its axis since only several slices are available, with no possibility of reorientation and interpolation as there is with MR images. 


\section{Anatomic reference}

There are several possibilities to analyze the anatomic position of a contact. The first one, the stereotactic atlas, is still used by many groups $[9,15,18,33]$. The contact, represented by its center, can be projected, after normalization and with reference to the $\mathrm{AC}-\mathrm{PC}$ midpoint, on the stereotactic Schaltenbrand and Bailey atlas discrete slices [34]. The atlas can also be projected, after deformation, on the patient MRI.

The geometric distortion in current clinical MRI (1.5-T machines) is now approaching tenths of a millimeter $[35,36]$. In view of these advances in technology, another possibility for analyzing the contact position is the projection of the electrode contact directly on the patient's MRI, which is generally chosen by those groups already working at least partially with direct MRI targeting $[14,37]$. In this case, it is possible to visualize not only the center of the contact but also its height and (or) diameter.

In addition, these two methods can be combined with the results of microelectrode recording as proposed by Herzog et al. who defined the dorsolateral margin of the STN by the analysis of intra-operative microrecordings [8].

\section{Interpretation}

Different ways to interpret the anatomic contact position have been used. Groups defining the contact by its center have often based their analysis on the classical approach, assigning one structure to the active contact $[16,18]$ or describing the position relative to certain structures or borders $[8,9,19]$. Herzog analyzed the position of the active contact in its length relative to the distance from the electrophysiologically determined dorsal STN border [8]. Following this approach they classified the active contacts into three groups: contacts lying above the STN $(+1.5 \mathrm{~mm}$ or above), contacts at the border zone of the STN $(-1.5 \mathrm{~mm}$ to $+1.5 \mathrm{~mm})$ and contacts inside the STN $(-1.5 \mathrm{~mm}$ or below). Voges et al. [18] considered three different anatomic positions of the contact center: effective contacts lying (1) within the STN, (2) outside the STN and within subthalamic fiber tracts and (3) at the border zone between the caudal third of the STN 
and the subthalamic white matter (STN-fiber interface). They also established the ratio of clinical improvement and stimulation energy and they accordingly took into account the fact that the therapeutic target could be some millimeters away from the effective contact. Saint-Cyr et al. [9] projected their results on Schaltenbrand \& Bailey atlas slices and they integrated in the analysis an average current spread of $3 \mathrm{~mm}$ radius around the cathode. In our group, we have already proposed an MRI-based quantitative approach based on the contact center and on fuzzy logic, taking into account the uncertainties in the identification of the contact [14]: when a contact could be identified exactly within one structure, the value 1 was assigned; when a structure was clearly not involved, the value 0 and when there was a doubt or when several structures were involved, we assigned 0.5. In the present study, we aimed to take this approach further. The first step was to introduce the real contact size which, in our opinion, is not negligible (diameter $=1.27 \mathrm{~mm}$; height $=1.5 \mathrm{~mm}$ ). Our stereotactic software (iPlan, Brainlab, Munich, Germany) enabled us to plot the electrode contact in the direction of the trajectory. Following our targeting concept, we used as an anatomic basis the preoperative MR images (WAIR sequence) with the manually outlined structures identified with the help of a 4.7T 3D MRI atlas (pixel size $0.25 \mathrm{~mm}^{3}$ ) [23] and the advanced knowledge of deep brain structures and fiber anatomy [13,38]. Taking both concepts together, we were able to interpret the electrode's anatomic position in 3D (on the reconstructed planes along the electrode) without stereotactic atlas-based normalization. In this way, we directly considered the patient's anatomy without reference to anatomic landmarks and avoided the reported risks, when using atlases, of geometric imprecision due to the interndividual variability of brain shape, structure size and structure location $[39,40]$. As in most cases the contact in its dimensions cannot be assigned to a single structure, we decided to introduce the membership concept. This approach takes into account, first, the imprecision in the determination of the contact position within the artifact, and second, the part of the contact covered by a given structure. In this way we were able to consider the extent of involvement of each structure.

Our results show that the lateral STN, the Forel's field H1 and especially the ZI are the structures most often found close to the contact, consistent with the results of other groups. In addition, our study indicates that the Forel's field H2 and the intermediate STN are certainly involved also. Hamel reported [6,33] that most contacts were located close to the dorsal border of STN or further dorsal within the subthalamic region. The other contacts were detected within the dorsal STN. The average position of all active contacts in their population coincided with the interface 
formed by the antero-dorso-lateral margin of the subthalamic nucleus, the ZI, and Forel's fields H2. Some of the studies using MRI-based techniques to identify the position of the active contact reported similar results $[9,18]$. In the opinion of Herzog et al. [8], it is crucial, to achieve optimal clinical results, to position the electrode at the dorsolateral border, without locating it exclusively in the subthalamic fiber tract. This seems to be confirmed by our results and by those of other groups $[6,13,19,41]$.

Considering the ratio of clinical improvement and the energy used, Voges et al. [18] reported a trend toward better results for active poles projecting onto subthalamic fiber tracts than with those placed either inside the STN or at the STN-fiber interfaces. Our comparison between the classical approach, considering only one structure per contact, and the membership concept confirms that in most cases more than one structure is present close to the contact (Table 3). The extentof involvement of all the structures changes with the membership concept. The intermediate STN and the AL rarely appear or do not appear at all with the first approach (Fig. 2). The influence of these areas in the DBS effect is unclear, as it is not usually documented in the literature, at least not specifically. Thus we draw no conclusion concerning the ansa lenticularis involvement because of its extremely low incidence in our study. Conversely the involvement of the intermediate STN seems robust and fits with the functional segmentation of STN $[4,42]$.

A detailed analysis based on the new concept is in progress on a larger patient population in order to correlate the anatomic contact position with the clinical result for all the contacts, not only for the therapeutic one. In the long term, we intend to integrate the stimulated volume (effective electric current) in our approach, as we agree with Butson et al. [32], Saint-Cyr et al. [9] and Voges et al. [18] that stimulation parameters influence the extent of stimulation and that the simple analysis of the contact position is only a first step in understanding the mechanism of action of DBS [43]. 


\section{CONCLUSIONS}

Postoperative imaging techniques are more and more part of routinely performed surgical protocols. We have shown that in addition to its utility as a quality control procedure, it can be used to evaluate the anatomic contact position on a routine basis. Given the size of the DBS contacts, the correlation between the clinical results and the contact position will probably be more precise if the contact is considered in its extent than if only the center of the contact is used. Also, the use of MRI allows reorientation along the contact direction and the 3D position analysis with regard to the individual anatomy. The contact membership concept allows a semiquantitative analysis, assigning a given contact to several structures with a weighted membership degree. This concept offers a promising approach for further studies of the mechanism of action of DBS in Parkinson's disease and DBS in general. Our preliminary results confirm that DBS probably acts through the three main structures, the lateral STN, ZI and FF.

\section{REFERENCES}

1. Hamani C, Richter E, Schwalb JM, Lozano AM (2005) Bilateral subthalamic nucleus stimulation for Parkinson's disease: a systematic review of the clinical literature. Neurosurgery 56(6):1313-1321

2. Krack P, Batir A, Van Blercom N, Chabardes S, Fraix V, Ardouin C, Koudsie A, Limousin PD, Benazzouz A, LeBas JF, Benabid AL, Pollak P (2003) Five-year follow-up of bilateral stimulation of the subthalamic nucleus in advanced Parkinson's disease. N Engl J Med 349(20):1925-1934

3. Krause M, Fogel W, Mayer P, Kloss M, Tronnier V (2004) Chronic inhibition of the subthalamic nucleus in Parkinson's disease. J Neurol Sci 219(1-2):119-124

4. Rodriguez-Oroz MC, Zamarbide I, Guridi J, Palmero MR, Obeso JA (2004) Efficacy of deep brain stimulation of the subthalamic nucleus in Parkinson's disease 4years after surgery: double blind and open label evaluation. J Neurol Neurosurg Psychiatry 75(10):1382-1385

5. Benazzouz A, Tai CH, Meissner W, Bioulac B, Bezard E, Gross C (2004) High-frequency stimulation of both zona incerta and subthalamic nucleus induces a similar normalization of basal ganglia metabolic activity in experimental parkinsonism. FASEB J 18(3):528-530

6. Hamel W, Fietzek U, Morsnowski A, Schrader B, Herzog J, Weinert D, Pfister G, Muller D, Volkmann J, Deuschl G, Mehdorn HM (2003) Deep brain stimulation of the subthalamic nucleus in Parkinson's disease: evaluation of active electrode contacts. J Neurol Neurosurg Psychiatry 74(8):1036-1046

7. Henderson JM, Pell M, O'Sullivan DJ, McCusker EA, Fung VS, Hedges P, Halliday GM (2002) Postmortem analysis of bilateral subthalamic electrode implants in Parkinson's disease. Mov Disord 17(1):133-137 
8. Herzog J, Fietzek U, Hamel W, Morsnowski A, Steigerwald F, Schrader B, Weinert D, Pfister G, Muller D, Mehdorn HM, Deuschl G, Volkmann J (2004) Most effective stimulation site in subthalamic deep brain stimulation for Parkinson's disease. Mov Disord 19(9):1050-1054

9. Saint-Cyr JA, Hoque T, Pereira LC, Dostrovsky JO, Hutchison WD, Mikulis DJ, Abosch A, Sime E, Lang AE, Lozano AM (2002) Localization of clinically effective stimulating electrodes in the human subthalamic nucleus on magnetic resonance imaging. J Neurosurg 97(5):1152-1166

10. Zincone A, Landi A, Piolti R, Appollonio I, Mariani CB, Pezzoli G, Gaini SM, Frattola L (2001) Physiologic study of the subthalamic volume. Neurol Sci 22(1):111-112

11. Duffner F, Schiffbauer H, Breit S, Friese S, Freudenstein D (2002) Relevance of image fusion for target point determination in functional neurosurgery. Acta Neurochir (Wien) 144(5):445-451

12. Ferroli P, Franzini A, Marras C, Maccagnano E, D'Incerti L, Broggi G (2004) A simple method to assess accuracy of deep brain stimulation electrode placement: pre-operative stereotactic CT postoperative MR image fusion. Stereotact Funct Neurosurg 82(1):14-19

13. Lemaire JJ, Coste J, Ouchchane L, Hemm S, Derost P, Ulla M, Siadoux S, Gabrillargues J, Durif F, Chazal J (2007) MRI anatomical mapping and direct stereotactic targeting in the Subthalamic region: relationsships between biological and anatomical data in 15 Parkinsonians. Int J CARS 2:75-85

14. Caire F, Derost P, Coste J, Bonny JM, Durif F, Frenoux E, Villeger A, Lemaire JJ (2006) Subthalamic deep brain stimulation for severe idiopathic Parkinson's disease. Location study of the effective contacts. Neurochirurgie 52(1):15-25

15. Nowinski WL, Belov D, Pollak P, Benabid AL (2004) A probabilistic functional atlas of the human subthalamic nucleus. Neuroinformatics 2(4):381-398

16. Starr PA, Christine CW, Theodosopoulos PV, Lindsey N, Byrd D, Mosley A, Marks WJ Jr (2002) Implantation of deep brain stimulators into the subthalamic nucleus: technical approach and magnetic resonance imaging-verified lead locations. J Neurosurg 97(2):370-387

17. Vayssière N, Vander Gaag N, Cif L, Hemm S, Verdier R, Frerebeau P, Coubes P (2004) Deep brain stimulation for dystonia confirms a somatotopic organization in the Globus Pallidus Internus. J Neurosurg 101(2):181-188

18. Voges J, Volkmann J, Allert N, Lehrke R, Koulousakis A, Freund HJ, Sturm V (2002) Bilateral highfrequency stimulation in the subthalamic nucleus for the treatment of Parkinson disease: correlation of therapeutic effect with anatomical electrode position. J Neurosurg 96(2):269-279

19. Zonenshayn M, Sterio D, Kelly PJ, Rezai AR, Beric A (2004) Location of the active contact within the subthalamic nucleus (STN) in the treatment of idiopathic Parkinson's disease. Surg Neurol 62(3):216225, discussion 225-226

20. Fahn S, Elton RL (1987) Unified Parkinson's disease rating scale. In: Fahn S, Marsden CD, Goldstein M (eds) Recent developments in Parkinson's disease. Macmillian, New York pp 153-163

21. Magnotta VA, Gold S, Andreasen NC, Ehrhardt JC, Yuh WT (2000) Visualization of subthalamic nuclei with cortex attenuated inversion recovery MR imaging. Neuroimage 11(4):341-346 
22. Derost P, Ouchchane L, Morand D, Ulla M, Llorca P, Barget M, Debilly B, Lemaire JJ, Durif F (2007) Is subthalamic nucleus deep brain stimulation (DBS-STN) appropriate to manage severe Parkinson disease in an elderly population. Neurology 68:1345-1355

23. Lemaire JJ, Caire F, Bony JM, Kemeny JL, Villéger A, Chazal J (2004) Contribution of 4.7 tesla MRI in the analysis of the MRI anatomy of the human subthalamic area. Acta Neurochir (Wien) 146(8):906907

24. Maintz JB, Viergever MA (1998) A survey of medical image regist ration. Med Image Anal 2(1):1-36

25. Wells WM III, Viola P, Atsumi H, Nakajima S, Kikinis R (1996) Multi-modal volume registration by maximization of mutual information. Med Image Anal 1(1):35-51

26. Pollo C, Villemure JG, Vingerhoets F, Ghika J, Maeder P, Meuli R (2004) Magnetic resonance artifact induced by the electrode Activa 3389: an in vitro and in vivo study. Acta Neurochir (Wien) 146(2):161164

27. Zadeh LA (1965) Fuzzy sets. Inf Control 8:338-353

28. Zadeh LA (1975) Fuzzy logic and approximate reasoning (in memory of Gregore Moisil). Synthèse 30:407-428

29. Ondo WG, Bronte-Stewart H (2005) The North American survey of placement and adjustment strategies for deep brain stimulation. Stereotact Funct Neurosurg 83(4):142-147

30. Elias WJ, Fu KM, Frysinger RC (2007) Cortical and subcortical brain shift during stereotactic procedures. J Neurosurg 107(5): 983-988

31. Miyagi Y, Shima F, Sasaki T (2007) Brain shift: an error factor during implantation of deep brain stimulation electrodes. J Neurosurg 107(5):989-997

32. Butson CR, Cooper SE, Henderson JM, McIntyre CC (2007) Patient-specific analysis of the volume of tissue activated during deep brain stimulation. Neuroimage 34(2):661-670

33. Hamel W, Schrader B, Weinert D, Herzog J, Volkmann J, Deuschl G, Muller D, Mehdorn HM (2002) MRI- and skull X-ray-based approaches to evaluate the position of deep brain stimulation electrode contacts - a technical note. Zentralbl Neurochir 63(2):65-69

34. Schaltenbrand G, Bailey P (1959) Introduction to stereotaxis with an atlas of the human brain. Thieme Verlag, New York, Stuttgart

35. Wang D, Strugnell W, Cowin G, Doddrell DM, Slaughter R (2004) Geometric distortion in clinical MRI systems Part II: correction using a 3D phantom. Magn Reson Imaging 22(9):1223-1232

36. Wang D, Strugnell W, Cowin G, Doddrell DM, Slaughter R (2004) Geometric distortion in clinical MRI systems Part I: evaluation using a 3D phantom. Magn Reson Imaging 22(9):1211-1221

37. Vayssiere N, Hemm S, Zanca M, Picot MC, Bonafe A, Cif L, Frerebeau P, Coubes P (2000) .J Neurosurg 93(5):784-790 
38. Lemaire JJ, Coste J, Ouchchane L, Caire F, Nuti C, Derost P, Cristini V, Gabrillargues J, Hemm S, Durif F, Chazal J (2007) Brain mapping in stereotactic surgery: a brief overview from the probabilistic targeting to the patient-based anatomic mapping. Neuroimage 37(Suppl 1):S109-S115

39. Kotter R, Wanke E (2005) Mapping brains without coordinates. Philos Trans R Soc Lond B Biol Sci 360(1456):751-766

40. Vayssiere N, Hemm S, Cif L, Picot MC, Diakonova N, El Fertit H, Frerebeau P, Coubes P (2002) Comparison of atlas- and magnetic resonance imaging-based stereotactic targeting of the globus pallidus internus in the performance of deep brain stimulation for treatment of dystonia. J Neurosurg 96(4):673679

41. Lanotte MM, Rizzone M, Bergamasco B, Faccani G, Melcarne A, Lopiano L (2002) Deep brain stimulation of the subthalamic nucleus: anatomical, neurophysiological, and outcome correlations with the effects of stimulation. J Neurol Neurosurg Psychiatry 72(1):53-58

42. Parent A, Williams, W (1996) Carpenter's human neuroanatomy. A Waverly Company, Baltimore

43. Hemm S, Mennessier G, Vayssiere N, Cif L, El Fertit H, Coubes P (2005) Deep brain stimulation in movement disorders: stereotactic coregistration of two-dimensional electrical field modeling and magnetic resonance imaging. J Neurosurg 103(6):949-955 